\title{
Solvent Retention of Contemporary Commercial Dentin Bonding Agents in a Demineralized Dentin Matrix
}

\author{
Georges Garcia \\ Karen Barros Parron Fernandes ${ }^{a}$ \\ Fernanda Cristina Pimentel Garciab \\ Paulo Henrique Perlatti D’Alpinoc \\ Nádia da Rocha Svizero ${ }^{d}$ \\ Linda Wang ${ }^{\mathrm{d}}$
}

Objectives: Solvents are ingredients in dentin-bonding agents (DBAs) that are essential to obtain efficient adhesion to dentin under wet-technique bonding protocol. However, an excess of solvents can compromise bonding durability. This study aimed to assess the retention of solvents present in different DBAs after their application to a demineralized dentin matrix.

Methods: Thirty-six specimens of bovine dentin were demineralized for 7 days in 0.5M EDTA and divided into six groups $n=6$ (Scotchbond primer, Adper Single Bond 2, Excite, AdheSE primer, Prime \& Bond NT and Xeno III). These specimens were individually saturated by the systems for 5 min and then kept in vials protected against light exposure. Each specimen was measured using a digital balance and then measured at the following intervals 10,20,30 sec, 1, 2 and 5 min thereafter. Data were analyzed by two-way ANOVA and Tukey tests (alfa=.05).

Results: There were significant differences evident in Excite, Prime \& Bond NT at 2 and $5 \mathrm{~min}$, respectively. There was no significant interaction between materials and time in all experimented time evaluated. The amount of solvent spontaneously evaporated was limited even in acetone-based specimens.

Conclusions: After DBAs are applied, professionals may facilitate their evaporation, since spontaneous evaporation is limited. (Eur J Dent 2010;4:293-297)

Key words: Solvents; Dentin-bonding systems; Dentin; Evaporation.

- a Restorative Dentistry of University North of Paraná - UNOPAR, Londrina, PR, Brazil.

b Faculty of Ceilândia, University of Brasilia-UnB, Ceilândia-DF, Brazil.

Department of Restorative Dentistry, GEO/Bandeirante University of São Paulo, São Paulo, SP, Brazil.

d Department of Operative Dentistry, Endodontics and Dental Materials of the School of Dentistry of Bauru, University of São Paulo, Bauru, SP, Brazil.

- Corresponding author: Profa. Dra. Linda Wang Department of Operative Dentistry, Endodontics and Dental Materials Alameda Octávio Pinheiro Brisolla, 9-75, Brasil.

Phone: +55-14-3235-8325 Fax: +55-14-3235-8523

E-mail: wanglinda01dyahoo.com.br/ wang.lindađusp.br

\section{INTRODUCTION}

Current dentin bonding agents (DBAs) contain solvents, which are among the most essential ingredients needed to establish an adequate dentin-resin interface. They are responsible for carrying resinous monomers into dentin after the etching step. ${ }^{1,2,3}$ Acetone, ethanol, and water are the solvents commonly present in DBAs, and they can be combined. ${ }^{4,5}$ Despite their relevant role, residual solvent is deleterious, as it can interfere with the polymerization process, ${ }^{6}$ reduce bonding strength, ${ }^{7-9}$ increase permeability of the adhesive 
layer,, 910 and lead to early degradation of the interface. ${ }^{11,12}$

The evaporation rate will vary depending on the composition of the DBAs. ${ }^{5}$ However, solvent properties are the most influential, mainly due to their vapor pressure and molecular weight. ${ }^{13,14}$ Additionally, the water content of the dentin, depending on the wet technique applied, as well as fluid from tubules may make it hard to eliminate, as the vapor pressure of the water-solvent combination is reduced. ${ }^{13}$ Pashley et al $^{13}$ investigated how water as a solvent and the solute concentration ratio can influence spontaneous evaporation.

Even in previous studies that investigated this property, ${ }^{15-18}$ only neat or experimental systems were used in combination with the dentin matrix. However, no commercial DBAs were verified. As commercial formulations present other substances as inorganic particles, initiators, and stabilizers, the evaporation/retention profiles have to be considered. Evaporation from commercial products was only assessed from vials, 5,16 not from dentin, which represents the clinical substrate.

Therefore, this study aimed to measure the retention of solvent present in different dentin bonding agents applied to a demineralized dentin matrix. The tested null hypotheses were: 1 . There is no difference in the amount of solvent retained through time; and 2. There is no difference in the amount of solvent retained in different tested commercial systems.

\section{METHODS AND MATERIALS}

The commercial dentin bonding agents used in this study are presented in Table 1.

Thirty-six specimens of dentin were obtained from bovine teeth, using a low-speed diamond saw and cut machine (Isomet, Buehler Ltd, Lake Bluff, IL 60049, USA). They were polished (APL 4 Arotec, Cotia, SP, Brasil) to obtain 2x2x2 mm cubes, which were measured using a digital caliper (Messen). The specimens were stored in a renewed $0.1 \%$ thymol solution under refrigeration until they were demineralized. The cubes were immersed in a beaker holding 0.5M EDTA solution with a $\mathrm{pH}$ of 7 and maintained under agitation (TE-420, Tecnal, Piracicaba, SP, Brazill for 7 days. This solution was renewed at the midpoint of the decalcification process. Finally, specimens were immersed in deionized water under agitation to avoid residual EDTA in the dentin cubes.

During the tests, the temperature and relative humidity were monitored, and they varied from 25.4 to $26.3^{\circ} \mathrm{C}$ and 75 to $79 \%$, respectively. One hundred $\mu \mathrm{L}$ aliquot from each DBA were dispensed in individual Eppendorf tubes, totalizing 36 specimens (six specimens for each DBA). For Xeno III, $50 \mu \mathrm{Ls}$ of each solution were combined.

\begin{tabular}{|c|c|c|c|}
\hline Dentin bonding system & Composition & Batch & Manufacturer \\
\hline $\begin{array}{l}\text { Adper Scotchbond } \\
\text { Multi-Purpose (Primer)-SC }\end{array}$ & $\begin{array}{l}2 \text { hidroxyethyl methacrylate (HEMA) }-30-40 \% \text {, } \\
\text { water, camphoroquinone }\end{array}$ & 5BA & 3MESPE \\
\hline Adper Single Bond 2 - SB & $\begin{array}{l}\text { Ethyl alcohol - 30-40\%, Bisfenol glycidyl methacrilate (Bis-GMA) } \\
-15-25 \%, \text { HEMA-10-20\%, Glycerol 1, } 3 \text { dimethacrylate - 5-15\%, } \\
\text { Acrylic acid copolymer and } \\
\text { itaconic acid - 5-15\%, Diurethane dimethacrylate - 2-8\%, water } \\
-2-8 \% \text {, silica }\end{array}$ & 5EP & 3MESPE \\
\hline Excite-EX & $\begin{array}{c}\text { Phosphonic acid acrylate }<12 \% \text {, HEMA }<21 \% \text {, } \\
\text { Dimethacrylates }<45 \% \text {, Alcohol }<26 \% \text {, Silica dioxide }\left(\mathrm{SiO}_{2}\right) \text {, } \\
\text { Initiators and stabilizers }\end{array}$ & H34505 & IVOCLAR-VIVADENT \\
\hline AdheSE (Primer) - AD & $\begin{array}{c}\text { HEMA }<25 \% \text {, Dimethacrylates }<75 \% \text {, Silica dioxide }\left(\mathrm{SiO}_{2}\right) \text {, } \\
\text { Initiators and stabilizers, water }\end{array}$ & H32396 & IVOCLAR-VIVADENT \\
\hline Prime \& Bond NT - PB & $\begin{array}{c}\text { Uretane dimethacrylate (UDMA), 5-62-1 resin, T resin, D resina, } \\
\text { silanized nanometric coloidal silica, PENTA, Cetilamine } \\
\text { hydrofluoride, initiators and stabilizers, water }\end{array}$ & 581837 & DENTSPLY \\
\hline Xeno III -X & $\begin{array}{c}\text { Liquid A: HEMA, purified water, Ethanol Urethane } \\
\text { dimethacrylates resin, butylated hydroxytoluene (BHT), } \\
\text { Highly dispersed silicon dioxide } \\
\text { Liquid B: Phosphoric acid modified polymethacrylate resin, Mono } \\
\text { fluoro phosphazene modified methacrylate resin. Urethane } \\
\text { dimethacrylate resin, butylated } \\
\text { hydroxytoluene (BHT), camphorquinone, } \\
\text { Ethyl-4-dimethylaminobenzoate. }\end{array}$ & 0506000482 & DENTSPLY \\
\hline
\end{tabular}


An aluminum sheet was used to externally involve Eppendorf tubes to reduce environmental light influence. Furthermore, they were also maintained in a hermetically closed thermal box to assure there was no light influence. Demineralized dentin cubes were individually removed from water and blotted dry. They were randomly immersed in the Eppendorf tubes with the tested DBAs for 5 minutes to be saturated by the material. Each specimen was subsequently removed from the Eppendorf tubes and, after a standardized removal of excess DBA, they were measured using a digital balance (Bioprecisa, mod. 2104N, São Paulo, SP, Brazil) with a $0.0001 \mathrm{~g}$ precision. An evaluation that took 5 minutes was done. The initial mass of each specimen was considered after a stabilization of the digital screen. Variations of mass, which represented a loss of solvent from DBA, were registered at the beginning and subsequently at 10,20, $30 \mathrm{sec}$ and 1, 2 and $5 \mathrm{~min}$. Data were normalized and calculated in percentages of the initial mass. These values were statistically analyzed and when a normal distribution was verified, they were compared through ANOVA and Tukey's tests with the confidence level set at 95\% lalfa=.05).

\section{RESULTS}

The medium and standard errors from tested materials are presented in Table 2. Figure 1 shows the profile of mass lost through time for each DBA.

There was a significant statistical difference when time and material were considered $(P<.05)$, but no interaction between them was verified $(P>$.05). Excite, Prime \& Bond NT were the only systems that revealed significant evaporation through time, at 2 and 5 minutes, respectively.

Through the total analyzed time, there was no statistical difference in the evaporation from the tested DBAs ( $P>$.05).

\section{DISCUSSION}

In the literature, there are reports of previous investigations of spontaneous evaporation of neat solvents, experimental systems, or commercial products without dentin matrix interference. ${ }^{15-18}$ In the present study, an in vitro test was proposed to measure mass loss of DBA from a demineralized dentin matrix. Bovine dentin was used since human specimens are getting harder to obtain because of ethical constraints. This substrate has been used in different studies as an adequate alternative during laboratory tests. ${ }^{19-22}$

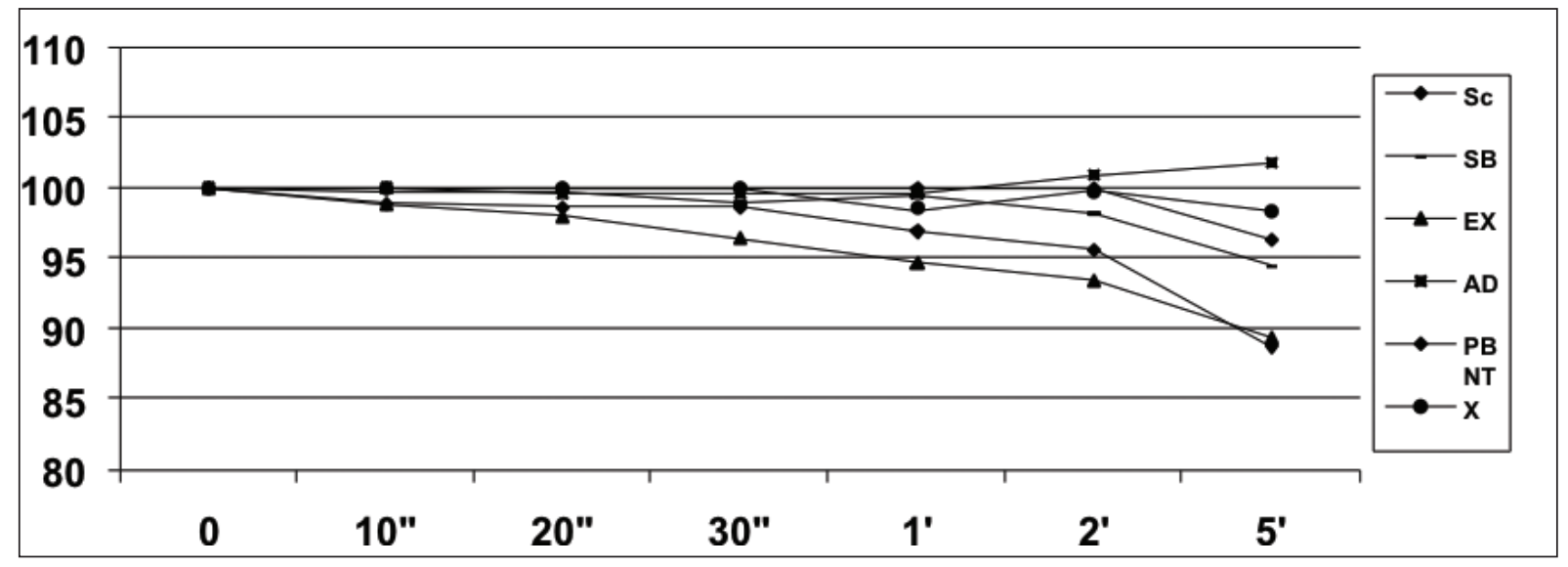

Figure 1. Profile of mass loss (\%) of dentin bonding systems for a total time of 5 minutes.

Table 2. Means $( \pm S D)$ of solvent retention $(\%)$ on demineralized dentin matrix through time.

\begin{tabular}{|c|c|c|c|c|c|c|}
\hline & $\mathrm{SC}$ & SB & EX & $A D$ & PB & $x$ \\
\hline $0 "$ & $100(0)^{A, a}$ & $100(0)^{A, a}$ & $100(0))^{A, a}$ & $100(0)$ A.a & $100(0)^{A, a}$ & $100(0)^{A, a}$ \\
\hline $10 "$ & $100(0) A, a$ & $99.74(0.26) \mathrm{A}, \mathrm{a}$ & $98.86(0.86)$ A,a & $100(0)$ A,a & $98.90(0.84)$ A.a & $100(0) A, a$ \\
\hline $20 "$ & $100(0)$ A,a & $99.74(0.26)$ A.a & $97.99(1.72)$ A.a & $99.64(0.27)^{\mathrm{A}, \mathrm{a}}$ & $98.62(1.12) A . a$ & $100(0){ }^{A, a}$ \\
\hline $30 "$ & $100(0)$ A,a & $98.94(0.78)$ A,a & $96.45(2.02) \mathrm{A}, \mathrm{a}$ & $99.72(0.27)$ A,a & $98.62(1.12)^{A, a}$ & $100(0)$ A,a \\
\hline $1^{\prime}$ & $100(0)^{A, a}$ & $99.48(1.06)^{A, a}$ & $94.73(3.30)^{A, a}$ & $99.66(1.14)^{A, a}$ & $96.93(1.57)^{A, a}$ & $98.61(0.88)$ A,a \\
\hline $2^{\prime}$ & $100(0)^{A, a}$ & $98.22(1.36)^{A, a}$ & $93.46(3.76)^{A, b}$ & $100.90(2.73)$ A,a & $95.63(1.84)^{A, a}$ & $99.78(1.11)^{A, a}$ \\
\hline $5^{\prime}$ & $96.37(1.80)^{A, a}$ & $94.55(3.64)^{A, a}$ & $89.42(2.98)^{A, b}$ & $101.80(2.89) \mathrm{A}, \mathrm{a}$ & $88.74(1.49)^{A, b}$ & $98.4(1.04)^{A, a}$ \\
\hline
\end{tabular}


Contemporary dentin bonding systems present resinous monomers combined to solvents such as neat acetone, ethanol, or water or a combination of them. ${ }^{1-3}$ A previous study showed that there was a greater spontaneous evaporation from acetone, since its vapor pressure and ebullition temperature are minor compared to other solvent properties, which results in a high evaporation speed. ${ }^{5}$ This rationale leads one to expect a similar profile from an acetone-based DBA when applied to a dentin substrate. ${ }^{3}$ However, in the present study, Excite, which is an ethanol-based product, showed a significant evaporation difference 2 minutes after the experiment began, while the acetonebased Prime \& Bond NT showed a difference only at the evaluation done 5 minutes after the experiment began. This profile clearly shows that even though a solvent is an essential factor, other ingredients in the formulated DBA can change the expected evaporation time. Furthermore, the interaction after its application to dentin can change its performance. When results from the present study are compared to data from studies by Abate et al, ${ }^{5}$ Cardoso et al, ${ }^{15}$ and Lima et al, ${ }^{16}$ it is evident that the dentin matrix acts as a physical barrier, so clinical attention is required to facilitate solvent evaporation.

Additionally, Fabre et $\mathrm{al}^{23}$ showed that commercial formulations of bonding agents have water sorption differences, which indicates that the presence of solvent can exacerbate water sorption, making it a negative factor that impacts bonding longevity.

When different DBS were compared in this study, no statistical differences were revealed among them at any of the times when they were evaluated, despite the fact that water-based DBAs (SC, SB, AD e X) showed minor evaporation followed by ethanol-based (EX) or acetone-based (PB) ones.

From a clinical point of view, when clinical time is employed to evaporate the solvent content 130 s), the amount of evaporation was insignificant for all tested materials. Thus, spontaneous solvent evaporation is not recommended after any application of DBAs to dentin, as they are largely retained, which is deleterious to adhesion durability. ${ }^{7-12}$ An active application of water-based DBAs is recommended to minimize solvent retention and assure adequate performance. ${ }^{21}$
When the data collected at the 5-minute evaluation time is observed, which is an unacceptable clinical time, no desirable evaporation amount was obtained for any DBA. This confirms that it is necessary to promote evaporation facilitation by using an air spray.

The results of the present study are in accordance with an investigation by Cardoso et al, ${ }^{15}$ which did not verify the statistical relevance of the spontaneous evaporation rate from an acetonebased system (One Step, BISCO) compared to a water-ethanol-based one (Single Bond, 3M ESPE) when monitored 1 and 2 minutes after the experiment began.

An air-spray is recommended to optimize solvent evaporation, ${ }^{17,18,24}$ and it has to be gently applied to avoid oxygen incorporation in the adhesive layer, which can negatively interfere with the monomer conversion. ${ }^{25} \mathrm{~A}$ recent study verified that the use of a warm air-dry stream is appropriate in a clinic to improve the bond strength of selfetching adhesives. ${ }^{14}$

This study does not ignore the evaporation facilitation of DBAs irrespective of the solvent content. As monomers and other components of solvents are responsible for the mechanism of adhesion, they will be always present, but it is important to avoid applying an excess amount or allowing direct contact with cells since they present an aggressiveness potential. 26,27 More investigations are necessary to verify the role of ingredients used as fillers and the contents and composition of monomers that act in combination with solvents.

\section{CONCLUSIONS}

Based on this limited laboratory study, it can be concluded that:

The null hypothesis (1) is rejected. There was a difference in the amount of evaporated material through the time for Excite and Prime \& Bond NT. The null hypothesis (2) is accepted. There was no difference in the amount of evaporated material among DBAs.

These results point out the need to provoke evaporation facilitation of solvents after any DBA application, as the spontaneous evaporation in dentin matrix is minimal, especially considering clinical time needed. 


\section{ACKNOWLEDGMENTS}

The authors would like to acknowledge 3M ESPE, Dentsply, and Ivoclar Vivadent for supplying the materials used in this study.

\section{REFERENCES}

1. Kanca $J 3^{\text {rd }}$. Effect of resin primer solvents and surface wetness on resin composite bond strength to dentin. Am J Dent 1992;5:213-215.

2. Perdigão J, Frankenberger R. Effect of solvent and rewetting time on dentin adhesion. Quintessence Int 2001;32:385390.

3. Reis AF, Oliveira MT, Giannini M, De Goes MF, Rueggeberg FA. The effect of organic solvents on one-bottle adhesives bond strength to enamel and dentin Oper Dent 2003;28:700706 .

4. Kanca $J 3^{\text {rd }}$. Effect of primer dwell time on dentin bond strength. Gen Dent 1998;46:608-612.

5. Abate PF, Rodriguez VI , Macchi RL. Evaporation of solvent in one-bottle adhesives. J Dent 2000;28:437-440.

6. Tay FR, Gwinnett AJ, Pang KM, Wei SH. Variability in microleakage observed in a total-etch wet bonding technique under different handling conditions. J Dent Res 1995;74:11681178.

7. Jacobsen T, Söderholm K-J. Some effects of water on dentin bonding. Dent Mater 1995;11:132-136.

8. Dickens $\mathrm{SH}, \mathrm{Cho} \mathrm{BH}$. Interpretation of bond failure through conversion and residual solvent measurements and weibull analyses of flexural and microtensile bond strengths of bonding agents. Dent Mater 2005;21:354-364.

9. Cadenaro M, Antoniolli F, Sauro S, Tay FR, Di Lenarda R, Prati C, Biasotto M, Contardo L, Breschi L. Degree of conversion and permeability of dental adhesives. Eur J Oral Sci 2005;113:525-530.

10. Hashimoto M, Tay FR, Ito S, Sano H, Kaga M, Pashley DH. Permeability of adhesive resin films. J Biomed Mater Res B Appl Biomater 2005;74:699-705.

11. Kato G, Nakabayashi N. The Durability of adhesion to phosphoric acid etched, wet dentin substrates. Dent Mater 1998;14:347-352.

12. Pashley DH, Tay FR, Yiu C, Hashimoto M, Breschi L, Carvalho RM, Ito $\mathrm{S}$. Collagen degradation by host-derived enzymes during aging. J Dent Res 2004;83:216-221.

13. Pashley EL, Zhang Y, Lockwood PE, Rueggeberg FA, Pashley $\mathrm{DH}$. Effects of HEMA on water evaporation from waterHEMA mixtures. Dent Mater 1998,14:6-10.

14. Garcia FC, Almeida JC, Osorio R, Carvalho RM, Toledano M. Influence of drying time and temperature on bond strength of contemporary adhesives to dentine. J Dent 2009;37:315320.
15. Cardoso P de C, Loguercio AD, Vieira LC, Baratieri LN, Reis A. Effect of prolonged application times on resin-dentin bond strengths. J Adhes Dent 2005;7:143-149.

16. Lima FG, Moraes RR, Demarco FF, Del Pino FA, Powers J. One-bottle adhesives: in vitro analysis of solvent volatilization and sealing ability. Braz Oral Res 2005;19:278-283.

17. Ikeda T, De Munch J, Shirai K, Hikita K, Inoue S, Sano H, Lambrechts P, Van Meerbeeck B. Effect of evaporation of primer components on ultimate tensile bond strengths of primes-adhesive mixture. Dent Mater 2005;21:1051-1058.

18. Yiu CKY, Pashley EL, Hiraishi N, King NM, Goracci C, Ferrari M, Carvalho RM, Pashley DH, Tay FR. Solvent and water retention in dental adhesive blends after evaporation. Biomaterials 2005;26:6863-6872

19. Nakamichi I, Iwaku M, Fusayama T. Bovine teeth as possible substitutes in the adhesion test. J Dent Res 1983;62:10761081.

20. Schilke R, Lisson JA, Bauss O, Geurtsen W. Comparison of the number and diameter of dentinal tubules in human and bovine dentine by scanning electron microscopic investigation. Arch Oral Biol 2000;45:355-361.

21. Ando S, Watanabe T, Tsubota K, Yoshida T, Irokawa A, Takamizawa T, Kurokawa H, Miyazaki M. Effect of adhesive application methods on bond strength to bovine enamel. $J$ Oral Sci 2008;50:181-186.

22. Uekusa S, Tsubota K, Tonegawa M, Tsuchiya H, Iwasa M, Kawamoto R, Takamizawa T, Miyazaki M. Microtensile bond strengths of single-step self-etch adhesive systems to bovine dentin. J Oral Sci 2007;49:183-189.

23. Fabre HSC, Fabre S, Cefaly DFG, Carrilho MRO, Garcia FCP, Wang L. Water sorption and solubility of dentin bonding agents light-cured with different light sources. $J$ Dent 2007:35:253-258.

24. Miyazaki M, Platt JA, Onose H, Moore BK. Influence of dentin primer application methods on dentin bond strength. Oper Dent 1996;21:167-172.

25. Hilton TJ, Schwartz RS. The effect of air thinning on dentin adhesive bond strength. Oper Dent 1995;20:133-137.

26. Koulaouzidou EA, Helvatjoglu-Antoniades M, Palaguias G, Karanika-Kouma A, Antoniades D. Cytotoxicity of dental adhesives in vitro. Eur J Dent 2009;3:3-9.

27. Ulker HE, Sengun A. Citotoxity evaluation of self-adhesive composite resin cements by dentin barrier test on 3D Pulp cells. Eur J Dent 2009;3:120-126. 